\title{
Hypertensive Peristalsis: A Rare Cause of Dysphagia in a Child
}

\author{
Mayank Jain ${ }^{1 *}$ and Jenisha Jain ${ }^{2}$ \\ Departments of ${ }^{1}$ Gastroenterology and ${ }^{2}$ Pediatrics, Choithram Hospital and Research Center, Indore, India
}

A 6-year-old male child presented with history of intermittent dysphagia for soilds and liquids for the past 6 months. The dysphagia worsened when taking ice creams and frequency of these episodes had increased from once in 15 days to twice in a week over the reported period. He had lost weight of $1 \mathrm{~kg}$ over the period of six months. He reported severe chest pain in nearly $25 \%$ of episodes. Clinical examination was normal. He underwent esophagogastroduodenoscopy which revealed normal findings (Fig. 1). High-resolution manometry (Fig. 2) showed normal lower esophageal sphincter pressures with high amplitude peristaltic contractions (mean amplitude $185 \mathrm{mmHg}$ ) in $70 \%$ of the wet swallows. There were no synchronus contractions and distal contractile integral was less than 5,000. Thus, a diagnosis of hypertensive (nutcracker) esophagus was made. The child was started on oral nifedipine during episodes of pain and is presently doing well.

Esophageal motor dysphagia is a rare problem in pediatric age group. Achalsia cardia is the most common etiology. ${ }^{1}$ "Nutcracker esophagus" is a term coined by Richter et $\mathrm{al}^{2}$ for the condition in which patients with non-cardiac chest pain and/or dysphagia exhibit peristaltic waves in the distal esophagus with mean amplitudes exceeding normal values by $>2$ SD. The manometric features may vary with time and some patients may develop achalasia. The place of nutcracker esophagus in spectrum of esophageal motility disorders needs further classification. ${ }^{1}$

To conclude, Nutcracker esophagus is a rare cause of esophageal dysmotility in pediatric population. High index of suspicion

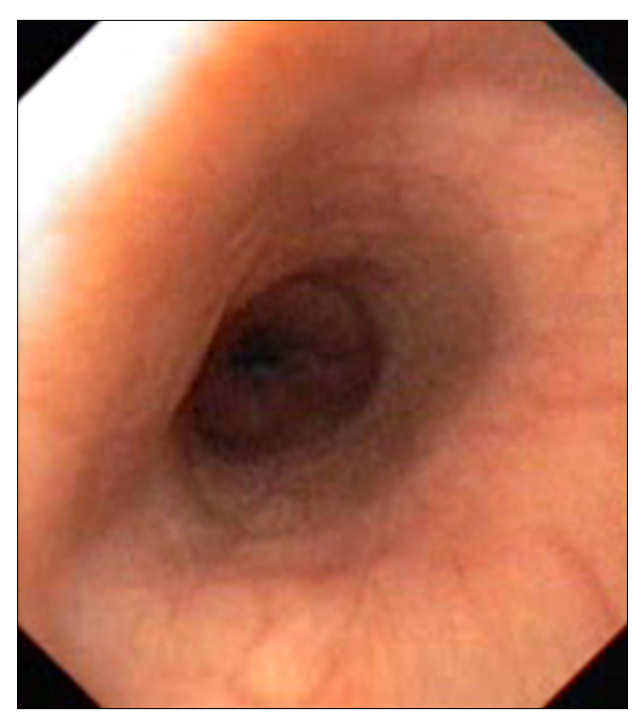

Figure 1. Endoscopic view of the esophagus.

Received: April 1, 2014 Revised: April 2, 2014 Accepted: April 2, 2014

(c) This is an Open Access article distributed under the terms of the Creative Commons Attribution Non-Commercial License (http://creativecommons. org/licenses/by-nc/3.0) which permits unrestricted non-commercial use, distribution, and reproduction in any medium, provided the original work is properly cited.

*Correspondence: Mayank Jain, MD, DNB

Department of Gastroenterology, Choithram Hospital and Research Center, Manik Bagh, Indore 452014, India

Tel: +91-895-924-5040, E-mail: mayank4670@rediffmail.com

Financial support: None.

Conflicts of interest: None.

Author contributions: Mayank Jain was done esophageal manometry; Jenisha Jain was seen and treated the case.

ORCID: Mayank Jain, http://orcid.org/0000-0003-1176-5167. 


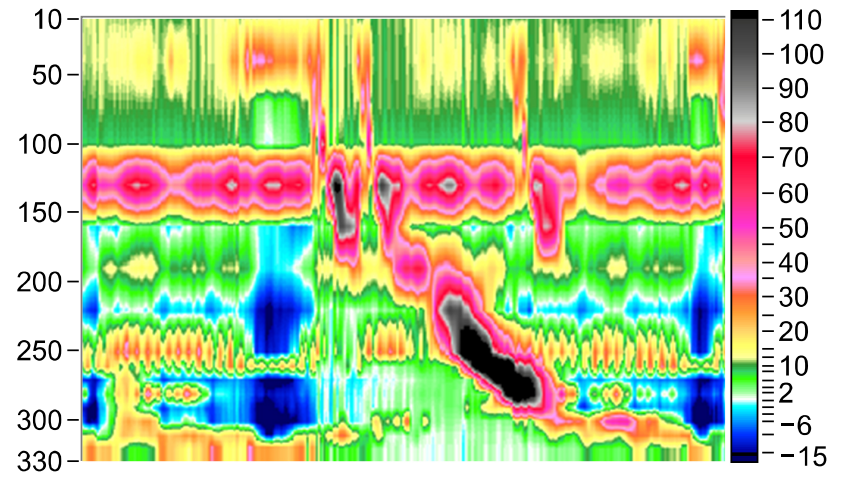

Figure 2. High-resolution manometric recording. and high-resolution manometry are required for proper diagnosis.

\section{References}

1. Colin D Rudolph, Manu R Sood. Achalsia and the motor disorders. In: Robert Wyllie, Jeffrey S Hyams, Marsha Kay, eds. Pediatric Gastrointestinal and Liver Disease. 4th ed. Philadelphia: Elsevier Saunders 2011:248-254.

2. Richter JE, Bradley LA, Castell DO. Esophageal chest pain: current controversies in pathogenesis, diagnosis, and therapy. Ann Intern Med 1989;110:66-78. 